\title{
Doença e estigma
}

\section{Disease and stigma}

\author{
Dilene Raimundo do Nascimento \\ Pesquisadora do Departamento de Pesquisa da Casa de Oswaldo Cruz \\ Av. Brasil, 4036/4 andar \\ 21040-361 Rio de Janeiro — RJ Brasil \\ dilenerai@hotmail.com
}

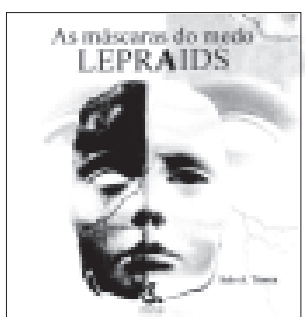

As máscaras do medo: lepraids Italo Tronca São Paulo, Editora da Unicamp, 2000, $150 \mathrm{p}$.
$\mathrm{O}$ novo livro de Italo Tronca traz importante contribuição ao campo da história das doenças. Com metodologia bastante inovadora, Tronca utiliza-se de fontes literárias de ficção para analisar historicamente os elementos culturais, sociais e políticos que produzem uma concepção estigmatizadora tanto da lepra quanto da Aids. Professor do Departamento de História da Universidade Estadual de Campinas (Unicamp), construiu justificada reputação no campo da história das doenças por suas pesquisas sobre a representação da lepra que resultaram em dois videocomentários realizados um em Pirapitingui, nos arredores de Itu, e o outro em Paricatuba, no Amazonas, ambos antigos asilos-colônias de hansenianos.

Nesse livro, Tronca estuda as representações sobre a lepra a partir do século XIX e sobre a Aids no final do século XX. Ele apresenta uma história cultural da doença, privilegiando a questão do imaginário social "como, talvez, o principal instituidor da história", por entender o imaginário como "aquela dimensão que dá à funcionalidade de cada sistema institucional sua orientação específica, que sobredetermina a escolha e as conexões das redes simbólicas, criação de cada época histórica".

Sua narrativa procura contrapor o discurso estético, a partir da literatura de ficção, ao discurso científico, isto é, o ponto de vista médico sobre a doença. Se o primeiro possui o estatuto da subjetividade, com licença poética para a invenção e a fantasia, considerado, portanto, irreal, o segundo possui o estatuto da verdade, expressão da objetividade, do concreto, portanto, do real.

Mas o autor demonstra que ambos trabalham com representações, isto é, ambos são construções sociais. Parte do princípio que um fenômeno biológico existe de forma independente do que possamos pensar ou imaginar em torno dele. Na verdade, somente ao se nominar esse fenômeno como doença é atribuído um sentido a ele. Dessa forma, a dor e os sintomas são definidos, dotados de significação e socialmente rotulados. Podemos observar que todo significado só é lógico para o indivíduo porque é socioculturalmente legitimado por seus semelhantes.

Por outro lado, as representações sociais, sendo produzidas e apreendidas no contexto das comunicações sociais, são necessariamente estruturas dinâmicas, caracteristicamente flexíveis e permeáveis, fazendo com que o estudo empírico das representações revele, freqüentemente, a concomitância de conteúdos mais estáveis e de conteúdos dinâmicos, mais sujeitos à mudança. As representações sociais são tanto a expressão de permanências culturais quanto o locus da multiplicidade, da diversidade e da contradição. 
Assim, as representações sociais são campos socialmente estruturados na interface de contextos sociais de curto e longo alcance histórico. E é com essa possibilidade de análise que, a meu ver, o autor trabalha. Considera a narrativa literária e a científica essenciais para revelar a complexa função cultural das representações sobre a doença em nossas sociedades, interpretando e contrapondo as alegorias existentes em um e em outro discursos.

Não há unanimidade nem entre os historiadores nem entre os críticos literários sobre a relação entre a literatura e a história. Por isso a coragem de Italo Tronca ao se propor explorar essa fronteira para escrever uma história cultural da lepra e da Aids, o que faz de forma magistral, principalmente em relação à lepra.

Nesse caso, a escolha de um magnífico romance que tematiza a lepra, a meu ver, não se dá por acaso, agrega-se às possibilidades romanescas dessa doença, o conhecimento que o autor tem acumulado ao longo dos anos de estudo sobre a lepra.

$\mathrm{Na}$ introdução, o autor explicita a sua escolha metodológica de analisar as alegorias contidas nos discursos literários e científicos e identifica três temas que, segundo ele, organizam as representações em torno da lepra e da Aids: a raça, a sexualidade e a geografia. Ressalta que tanto os temas quanto os elementos alegóricos em ambos os discursos aparecem em constante interpenetração entre eles, não valendo tratá-los com esquemas teóricos rígidos.

Justifica a escolha das fontes por se tratar de textos quase todos em língua inglesa, principalmente norte-americana, considerando que não são nem mais nem menos importantes que as de outras culturas ocidentais, mas que do ponto de vista alegórico são bem mais ricas.

O livro contém cinco capítulos onde o autor trabalha com 12 narrativas literárias cujo tema central é a doença, seja a lepra seja a Aids, distribuídas de forma desigual nos capítulos. Dessas narrativas, ele extrai o modo alegórico como as doenças são representadas e, em um exercício de aproximação entre a lepra no século XIX e a Aids no século XX, analisa historicamente a conjuntura política e social de cada época.

No primeiro capítulo, o próprio título 'Raça: mai Pake, o perigo amarelo', indica o tema tratado. As quatro narrativas utilizadas aqui são trechos traduzidos e adaptados por Tronca do romance épico Hawaí, de James Michener. Como o próprio autor sinaliza, o que à primeira vista poderia parecer "uma boa história de aventuras", uma análise das alegorias expressas nas imagens literárias, revela fundamentalmente uma política racista implementada na segunda metade do século XIX nos Estados Unidos.

A ficção inicia em 1870 e o personagem leproso das narrativas é um chinês, cuja esposa é criada de um médico americano, missionário protestante, que chegara ao Havaí em 1820. Na seqüência, as quatro narrativas acompanham a trajetória do casal chinês desde a busca de tratamento para os primeiros sinais físicos, logo confirmados como mai Pake, isto é, lepra, a tentativa de ocultação da doença, até a denúncia à polícia feita pelo médico americano, por dever moral.

Mas Tronca, ao analisar as narrativas, destaca elementos alegóricos que indicam outros significados contidos no texto como o antagonismo 
entre a medicina ocidental e a medicina chinesa, entre médicos e charlatães, entre o bem e o mal e, finalmente, auxiliado por leitura secundária, a ameaça do ressurgimento da lepra na Europa e nos Estados Unidos durante o apogeu da expansão ocidental. Essa expansão implicou, em contrapartida, um movimento imigratório de asiáticos em direção ao Havaí e aos Estados Unidos. Dentre esses, os chineses principalmente foram identificados como populações prevalecentemente leprosas e com isso passaram a ser vistos como um perigo: o "perigo amarelo". A construção de uma América segura à essa época tinha como base a afirmação da doutrina racista.

No segundo capítulo, intitulado 'Luxúria: a doença e o sublime', o autor analisa a narrativa 5, outro trecho do romance de Michener que dá seqüência à trajetória do casal de chineses. Essa narrativa descreve os horrores de Molokai, leprosário construído na península de Kalawao, na segunda metade do século XIX, para onde os leprosos eram levados compulsoriamente. Lá não havia lei, não havia ordem e a devassidão imperava.

Tronca ressalta que a ficção "revitaliza um antigo tema da alegoria cristã ao explorar a associação entre a lepra e a luxúria". Por outro lado, a existência do leprosário expressa o confinamento dos doentes, portadores do mal.

No capítulo 3, 'Os lugares do mal', o autor trata alegoricamente da geografia da doença. Lança mão de trechos do romance de Jack London, Koolau, el leproso, consubstanciados na narrativa 6. Koolau é um líder numa comunidade de leprosos que vivem isolados numa ilha do Havaí que resistem ao degredo compulsório no leprosário de Molokai. Tronca analisa a narrativa de London, escritor de tendência socialista, como expressão de revolta e piedade contra a brutal política de perseguição aos doentes de lepra no Havaí. Como alternativa aos horrores de Molokai, cria-se outra ilha como "lugar" da lepra.

As narrativas 7,8 e 9 são trechos de contos brasileiros que localizam a figura do leproso em ranchos à beira de estradas desertas. De uma forma ou de outra, o "leproso e sua doença estão encapsulados em lugares seguros, distantes de nós, do mundo dos sãos".

Os capítulos 4 e 5 tratam da representação da Aids que surge mais de cem anos depois dos acontecimentos que envolvem a lepra no Havaí. Novamente, no início de 1980, estamos às voltas com uma doença que estigmatiza, que deve ser ocultada e, em última instância, confinada, nesse caso, nos "grupos de risco".

Em 'Aids: uma nova estrela má', Tronca utiliza trechos do romance You are here, de Pam Lewis consubstanciados na narrativa 10, que em nenhum momento explicita o nome da doença apesar de conter os elementos alegóricos que a identificam. Tronca chama atenção para a associação entre "homossexualismo, infidelidade, doença e morte numa implícita e rigorosa seqüência de causa e efeito".

A mulher, personagem principal do romance, após a morte do marido por suicídio ante seu diagnóstico de Aids, recusa-se a fazer o teste HIV por se sentir imune à doença, justificando pela falta de relações sexuais entre eles. Mas Tronca defende que existe um significado subjacente que é considerar a Aids como um problema de homossexuais masculinos 
e que a mulher, esposa fiel e mãe de família, estaria a salvo do vírus. Essa construção epidemiológica da Aids empresta um caráter moralizante à doença.

Tronca segue, ao longo desse capítulo, nessa linha de análise baseado na narrativa de Randy Shilts, um jornalista norte-americano, que, na busca para descobrir as origens da epidemia de Aids, realizou mais de mil entrevistas com pessoas envolvidas nos vários âmbitos com a doença nos Estados Unidos.

No capítulo 5, 'Os lugares da Aids: a geografia da diferença', o autor aponta a Aids como uma doença essencialmente urbana, ao contrário da lepra. No mais, se não se pode afirmar em definitivo a origem da Aids, tenta-se sempre culpabilizar o "outro". Se, por um lado, os Estados Unidos localizavam a origem da síndrome nos negros africanos e nos haitianos, para os franceses e os europeus em geral, segundo Tronca, a Aids tinha o rótulo de made em USA.

Italo Tronca conclui dizendo que, "hoje, a perspectiva de a Aids tornarse um mal, se não curável, pelo menos crônico, parece inclinar o pêndulo alegórico para a esperança, até o advento de uma nova estrela má, que aponte o retorno do medo, conforme o testemunho dos tempos".

Finalizando, a leitura deste livro é bastante instigante, suas narrativas selecionadas prendem a atenção do leitor e ao mesmo tempo, pela proposta do autor, leva-nos também a um exercício de pensar as alegorias contidas nas narrativas. Qualquer limite que essa abordagem utilizada por Italo Tronca possa impor academicamente, ele resolve rompendo com o discurso acadêmico. O livro de Italo Tronca nos traz uma grande contribuição que é expor a complexidade do processo de construção social das doenças. 